\title{
Curative Resection for Metachronous Pulmonary Metastases from Colorectal Cancer: Analysis of Survival Rates and Prognostic Factors
}

\author{
Myong Hoon Ihn, MD 1 \\ Duck-Woo Kim, MD, PhD' \\ Sukki Cho, MD, PhD² \\ Heung-Kwon Oh, MD' \\ Sanghoon Jheon, $\mathrm{MD}, \mathrm{PhD}^{2}$ \\ Kwhanmien Kim, MD, PhD² \\ Eun Shin, MD ${ }^{3}$ \\ Hye Seung Lee, MD, $\mathrm{PhD}{ }^{3}$ \\ Jin-Haeng Chung, MD, $\mathrm{PhD}^{3}$ \\ Sung-Bum Kang, $\mathrm{MD}, \mathrm{PhD}^{1}$
}

Departments of ${ }^{1}$ Surgery, ${ }^{2}$ Thoracic and Cardiovascular Surgery, and ${ }^{3}$ Pathology, Seoul National University Bundang Hospital, Seoul National University College of

Medicine, Seongnam, Korea

\begin{abstract}
Purpose
Prognostic factors in patients with pulmonary metastases (PM) from colorectal cancer (CRC) are still controversial. This study assessed oncologic outcomes and prognostic factors in patients with metachronous PM from CRC.
\end{abstract}

\section{Materials and Methods}

Between June 2003 and December 2011, 122 patients with CRC underwent curative resection of PM detected at least 4 months after $\mathrm{CRC}$ resection. Clinico-pathological factors selected from the prospectively maintained database were analyzed retrospectively.

\section{Results}

The median disease-free interval (DFI) between resection of the primary tumor and detection of PM was 22.0 months (range, 4 to 85 months). Solitary PM were detected in 77 patients (63.1\%), with a median maximal tumor diameter of $12.0 \mathrm{~mm}$ (range, 2 to $70 \mathrm{~mm}$ ). Of 52 patients who underwent mediastinal lymph node (LN) dissection, eight patients had LN involvement. Five-year overall survival and disease-free survival (DFS) rates after initial pulmonary metastasectomy were $66.4 \%$ and $50.9 \%$, respectively. DFI, mediastinal LN involvement, and the number and distribution of PM were significantly prognostic factors for DFS. In multivariable analysis DFI $\geq 12$ months, solitary lesion, and absence of mediastinal LN involvement were independently prognostic for DFS. Of the 122 patients, 48 patients (39.3\%) developed recurrent PM a median 13.0 months after initial pulmonary metastasectomy. Recurrent DFI was independently prognostic of DFS in patients who underwent repeated pulmonary metastasectomy.

\section{Conclusion}

There is a potential survival benefit for patients with metachronous PM from CRC who undergo pulmonary metastasectomy, even those with recurrent PM. Pulmonary metastasectomy should be considered in selected patients, particularly those with longer DFI, solitary lesions, and absence of mediastinal LN involvement.

Key words

Pulmonary metastasis, Colorectal neoplasms,

Disease-free interval, Metastasectomy

\section{Introduction}

Colorectal cancer $(\mathrm{CRC})$ is a common cause of cancerrelated death, with increased incidence over the past 25 years $[1,2]$. Despite advances in treatment, it is expected that more than $50 \%$ of patients undergoing resection for CRC will experience disease recurrence $[3,4]$. Pulmonary metastases
(PM) have been reported in approximately $10 \%$ to $25 \%$ of patients with CRC $[5,6]$. Patients who underwent curative resection of CRC and isolated PMs had 5-year overall survival (OS) rates of $27 \%$ to $68 \%$ [6-8], whereas patients with untreated metastatic disease had a median survival of less than 10 months and a 5-year survival rate of less than $5 \%$ $[9,10]$.

Surgical resection combined with adjuvant chemotherapy 
is the current treatment of choice for patients with resectable PM, whereas chemotherapy is the treatment of choice for patients with unresectable PM [11]. Despite development of several novel chemotherapeutic and targeted agents for treatment of metastatic CRC, which might prolong disease-free survival (DFS) and OS, the long-term results have been less than satisfactory in patients with unresectable PM [12]. Surgical resection has been accepted as the only radical treatment available for PM and has shown benefits in cases where metastases are confined to the lungs and complete resection (R0) is possible [13,14]. However, the recurrence rate after pulmonary metastasectomy is still as high as $68 \%$, with the remaining lung being the most common site of recurrence [6]. Therefore, identification of factors prognostic of the outcomes of pulmonary metastasectomy in patients with PM from CRC is important.

Many factors have been reported to show association with the prognosis of patients with PM from CRC who undergo pulmonary metastasectomy, including number of pulmonary lesions, patient age, stage of the primary tumor, history of liver resection, maximum tumor size, histology of the primary tumor, disease-free interval (DFI) between primary CRC surgery and detection of PM, and carcinoembryonic antigen (CEA) concentration $[2,6,13]$. However, these studies included small numbers of patients, patients who underwent $\mathrm{R} 1$ and/or R2 resection, or patients with both synchronous and metachronous lesions, and few studies have assessed therapeutic strategies in patients who develop recurrent PM after the first pulmonary metastasectomy.

This study was therefore designed to determine prognostic factors of survival in patients who underwent complete resection for metachronously developed PM. In addition, outcomes and factors prognostic of repeated pulmonary metastasectomy for recurrent PM were analyzed.

\section{Materials and Methods}

In this study patients who underwent curative pulmonary resection for metachronous PM from CRC at Seoul National University Bundang Hospital between June 2003 and June 2011 were analyzed retrospectively. Curative pulmonary resection was defined as histologically-proven complete resection for isolated pulmonary metastatic lesions, confined to the lungs without local or extrapulmonary recurrence on computed tomography (CT) scans of the chest, abdomen, and pelvis and positron emission tomography (PET) of the entire body. Metachronous PM was defined as a new lesion detected at least 4 months after curative CRC surgery, as reported in a previous study [15]. Patients with synchronous
PM and those who underwent pulmonary metastasectomy with positive margins (R1 resection) or gross residual disease ( $\mathrm{R} 2$ resection), or those with evidence of distant metastasis or concurrent malignancy at pretreatment work-up, except for resectable hepatic metastases, were excluded.

Patients were followed up after CRC surgery according to our postoperative surveillance protocol. Patients underwent physical examination and measures of serum CEA levels every 3 months for 2 years, and then every 6 months for 5 to 8 years. Contrast-enhanced CT scans of the chest, abdomen, and pelvis were performed every 3 to 6 months during the first 2 years, and then every 6 to 12 months thereafter, and total colonoscopy was performed every 1 to 2 years. PET-CT was selectively performed if needed, mainly in patients with suspected recurrence. Diagnosis of PM was based on imaging findings on chest X-ray or CT. Indeterminate lesions detected in the lungs after CRC surgery were discussed by a multi-disciplinary team (MDT), consisting of a colorectal surgeon, thoracic surgeon, radiologist, pathologist, and medical oncologist; assessment by chest CT was performed 3 months later. Lesions that became larger and more prominent were defined as PM. The onset of PM in those patients was defined as the time after CRC surgery when the new pulmonary nodules were first detected.

Treatment decisions were made by the MDT. The selection criteria for pulmonary metastasectomy were defined as described previously [16]: (1) no evidence of uncontrolled primary site, (2) no evidence of extrathoracic metastasis, (3) chest $\mathrm{CT}$ showing that complete resection was possible regardless of the number of lesions, (4) tumors in the bilateral thorax not considered a contraindication, and (5) patient's general condition should be able to tolerate surgery, with remaining respiratory function sufficient for normal daily life. Further resection in patients who developed additional PM was performed according to the above-mentioned criteria. Pulmonary metastasectomy of metastatic nodules consisted of non-anatomical resection (precision excision and wedge resection) and anatomical resection (segmental resection and lobectomy). Precision excision was defined as nonanatomical resection by application of electrocautery just beneath the lesion, leaving essentially all normal lung tissue. Wedge resection through thoracotomy or video-assisted thoracic surgery was the procedure of choice, although lobectomy was performed on metastatic lesions located deep within the pulmonary parenchyma. Mediastinal lymph node (LN) dissection was performed selectively.

Surgical specimens were assessed histologically. All specimens were fixed in formalin and sectioned in the oblique coronal plane to include the largest plane of the tumor, and all sections were stained with hematoxylin and eosin, followed by examination by light microscopy.

Collection and analysis of data was performed in June 
Table 1. Patient characteristics

\begin{tabular}{|c|c|c|c|c|}
\hline Characteristic & $\begin{array}{c}\text { Total } \\
(n=176)\end{array}$ & $\begin{array}{l}\text { Synchronous } \\
\text { PM (n=54) }\end{array}$ & $\begin{array}{l}\text { Metachronous } \\
\text { PM (n=122) }\end{array}$ & p-value \\
\hline \multicolumn{5}{|l|}{ Age (yr) } \\
\hline$\leq 60$ & $85(48.3)$ & $30(55.6)$ & $55(45.1)$ & 0.25 \\
\hline$>60$ & $91(51.7)$ & $24(44.4)$ & $67(54.9)$ & \\
\hline Mean \pm SD & $60.3 \pm 11.7$ & $58.3 \pm 12.6$ & $61.3 \pm 11.2$ & 0.11 \\
\hline \multicolumn{5}{|l|}{ Sex } \\
\hline Male & $114(64.8)$ & $31(57.4)$ & $83(68.0)$ & 0.23 \\
\hline Female & $62(35.2)$ & $23(42.6)$ & $39(32.0)$ & \\
\hline \multicolumn{5}{|l|}{ Body mass index $\left(\mathrm{kg} / \mathrm{m}^{2}\right)$} \\
\hline$\leq 25$ & $131(74.4)$ & $43(79.6)$ & $88(72.1)$ & 0.35 \\
\hline$<25$ & $45(25.6)$ & $11(20.4)$ & $34(27.9)$ & \\
\hline Mean \pm SD & $23.2 \pm 3.2$ & $22.8 \pm 3.4$ & $23.4 \pm 3.0$ & 0.27 \\
\hline \multicolumn{5}{|l|}{ Primary tumor location } \\
\hline Colon & $78(44.3)$ & $23(42.6)$ & $55(45.1)$ & 0.87 \\
\hline Rectum & $98(55.7)$ & $31(57.4)$ & $67(54.9)$ & \\
\hline \multicolumn{5}{|l|}{ Tumor stage $^{a)}$} \\
\hline 1 & $7(4.0)$ & $2(3.7)$ & $5(4.1)$ & $<0.001$ \\
\hline 2 & $26(14.8)$ & $2(3.7)$ & $24(19.7)$ & \\
\hline 3 & $86(48.9)$ & $14(25.9)$ & $72(59.0)$ & \\
\hline 4 & $57(32.4)$ & $36(66.7)$ & $21(17.2)$ & \\
\hline \multicolumn{5}{|l|}{ Histology of primary tumor } \\
\hline Well differentiated & $17(9.7)$ & $5(9.3)$ & $12(9.8)$ & 0.43 \\
\hline Moderately differentiated & $149(84.7)$ & $44(81.5)$ & $105(86.1)$ & \\
\hline Mucinous or poorly differentiated & $10(5.7)$ & $5(9.3)$ & $5(4.1)$ & \\
\hline \multicolumn{5}{|l|}{ Previous hepatectomy } \\
\hline No & $151(85.8)$ & $43(79.6)$ & $108(88.5)$ & 0.16 \\
\hline Yes & $25(14.2)$ & $11(20.4)$ & $14(11.5)$ & \\
\hline \multicolumn{5}{|l|}{ Adjuvant therapy for CRC } \\
\hline No & $14(8.0)$ & $9(16.7)$ & $5(4.1)$ & 0.01 \\
\hline Yes & $162(92.0)$ & $45(83.3)$ & $117(95.9)$ & \\
\hline \multicolumn{5}{|l|}{ No. of prior regimens } \\
\hline 0 & $14(8.0)$ & $9(16.7)$ & $5(4.1)$ & $<0.001$ \\
\hline 1 & $125(71.0)$ & $41(75.9)$ & $84(68.9)$ & \\
\hline 2 & $29(16.5)$ & $1(1.9)$ & $28(23.0)$ & \\
\hline 3 & $7(4.0)$ & $3(5.6)$ & $4(3.3)$ & \\
\hline No data & $1(0.6)$ & 0 & $1(0.8)$ & \\
\hline \multicolumn{5}{|l|}{ Prior systemic chemotherapeutic agents } \\
\hline 5 -FU & $131(74.4)$ & $43(79.6)$ & $88(72.1)$ & - \\
\hline Oxalipatin & $95(54.0)$ & $26(48.1)$ & $69(56.5)$ & \\
\hline Irinotecan & $16(9.1)$ & $4(7.4)$ & $12(9.8)$ & \\
\hline Capecitabine & $56(31.8)$ & $14(25.9)$ & $42(34.4)$ & \\
\hline Bevacizumab & $11(6.2)$ & $4(7.4)$ & $7(5.7)$ & \\
\hline \multicolumn{5}{|l|}{ Disease-free interval (mo) } \\
\hline$<12$ & $75(42.6)$ & $54(100)$ & $21(17.2)$ & $<0.001$ \\
\hline$\geq 12$ & $101(57.4)$ & 0 & $101(82.8)$ & \\
\hline Median (range) & $13.0(0-85)$ & $0.0(0-3)$ & $22.0(4-85)$ & \\
\hline \multicolumn{5}{|l|}{ No. of pulmonary tumors } \\
\hline Solitary & $101(57.4)$ & $24(44.4)$ & $77(63.1)$ & 0.03 \\
\hline Multiple & $75(42.6)$ & $30(55.6)$ & $45(36.9)$ & \\
\hline Median (range) & $1.0(1-21)$ & $2.0(1-21)$ & $1.0(1-14)$ & \\
\hline
\end{tabular}


Table 1. Continued

\begin{tabular}{|c|c|c|c|c|}
\hline Characteristic & $\begin{array}{c}\text { Total } \\
(n=176)\end{array}$ & $\begin{array}{l}\text { Synchronous } \\
\text { PM (n=54) }\end{array}$ & $\begin{array}{l}\text { Metachronous } \\
\text { PM (n=122) }\end{array}$ & p-value \\
\hline \multicolumn{5}{|l|}{ Maximal tumor size (mm) } \\
\hline$\leq 20$ & $152(86.4)$ & $46(85.2)$ & $106(86.9)$ & 0.81 \\
\hline$>20$ & $24(13.6)$ & $8(14.8)$ & $16(13.1)$ & \\
\hline Median (range) & $12.0(2-70)$ & $11.0(3-60)$ & $12.0(2-70)$ & \\
\hline \multicolumn{5}{|l|}{ Distribution of metastases } \\
\hline Unilateral & $144(81.8)$ & $36(66.7)$ & $108(88.5)$ & 0.01 \\
\hline Bilateral & $32(18.2)$ & $18(33.3)$ & $14(11.5)$ & \\
\hline \multicolumn{5}{|l|}{ Resection $^{\text {b) }}$} \\
\hline Non-anatomical & $132(75.0)$ & $42(77.8)$ & $90(73.8)$ & 0.71 \\
\hline Anatomical & $44(25.0)$ & $12(22.2)$ & $32(26.2)$ & \\
\hline \multicolumn{5}{|l|}{ Mediastinal LN dissection } \\
\hline No & $106(60.2)$ & $36(66.7)$ & $70(57.4)$ & 0.32 \\
\hline Yes & $70(39.8)$ & $18(33.3)$ & $52(42.6)$ & \\
\hline \multicolumn{5}{|l|}{ Mediastinal LN involvement } \\
\hline No & $61(34.7)$ & $17(31.5)$ & $44(36.1)$ & 0.36 \\
\hline Yes & $9(5.1)$ & $1(1.9)$ & $8(6.6)$ & \\
\hline No data & $106(60.2)$ & $36(66.7)$ & $70(57.4)$ & \\
\hline \multicolumn{5}{|l|}{ Chemotherapy after metastasectomy } \\
\hline No & $13(7.4)$ & $2(3.7)$ & $11(9.0)$ & 0.27 \\
\hline Cytotoxic agent only & $139(79.0)$ & $42(77.8)$ & $97(79.5)$ & \\
\hline Cytotoxic agent+targeted agent & $24(13.6)$ & $10(18.5)$ & $14(11.5)$ & \\
\hline
\end{tabular}

Values are expressed as number (\%) unless otherwise indicated. PM, pulmonary metastases; SD, standard deviation; CRC, colorectal cancer; 5-FU, 5-fluorouracil; LN, lymph node. a)Using the seventh edition of the American Joint Committee on Cancer staging system, b) Non-anatomical resection included precision excision and wedge resection; anatomical resection included segmental resection and lobectomy.

2014. Factors recorded included patient age, sex, body mass index, primary tumor location, presence of liver metastases, tumor staging, histology of the primary tumor, neoadjuvant and/or adjuvant chemoradiotherapy for primary CRC, DFI between initial resection of the primary CRC and detection of PM, number and maximal diameter of PMs, distribution of PMs, types of resection performed, mediastinal LN dissection and involvement, chemotherapy after pulmonary metastasectomy, and OS and DFS. In addition, OS and DFS in patients with recurrent PM, defined as a new pulmonary nodule or development of a tumor after initial pulmonary metastasectomy, were measured from the time of the first pulmonary metastasectomy to the time of death or recurrence. DFI and recurrent DFI were dichotomized according to $<12$ months and $\geq 12$ months, as reported in a previous study [17]. The sizes of all metastatic tumors were dichotomized as $\leq 20 \mathrm{~mm}$ and $>20 \mathrm{~mm}$.

The Kaplan-Meier method and log rank test were used for evaluation of the prognostic effect of each variable on survival and 1 multivariable Cox proportional hazards regression analysis was performed for analysis of factors related to survival. Patients were subgrouped according to factors significantly prognostic of DFS, and rates of survival and recurrent PM in the subgroups were compared. Categorical variables were analyzed using the chi-squre test or Fisher exact test, and continuous variables were compared using Student's t test. p-values $\leq 0.05$ were considered statistically significant. Statistical analyses were performed using SPSS ver. 18.0 (SPSS Inc., Chicago, IL). This study was approved by the Ethics Review Board at Seoul National University Bundang Hospital, Korea.

\section{Results}

Between June 2003 and June 2011, 2,529 patients underwent curative CRC surgery at our hospital. Of these, 167 patients $(6.6 \%)$ developed PM, including 54 patients $(2.1 \%)$ with synchronous and 113 patients $(4.5 \%)$ with metachronous lesions. Of the latter 113 patients, 94 patients underwent 
Table 2. Univariable and multivariable analysis of factors prognostic of 5-year DFS after pulmonary metastasectomy

\begin{tabular}{|c|c|c|c|c|c|c|}
\hline Characteristic & $\begin{array}{c}\text { No. } \\
(\mathrm{n}=122)\end{array}$ & $\begin{array}{c}5-\mathbf{Y r} \\
\text { DFS (\%) }\end{array}$ & p-value & HR & $95 \% \mathrm{CI}$ & p-value \\
\hline \multicolumn{7}{|l|}{ Age (yr) } \\
\hline$\leq 60$ & 55 & 49.4 & 0.23 & - & & - \\
\hline$>60$ & 67 & 50.0 & & - & - & \\
\hline \multicolumn{7}{|l|}{ Sex } \\
\hline Male & 83 & 48.3 & 0.67 & - & & - \\
\hline Female & 39 & 57.7 & & - & - & \\
\hline \multicolumn{7}{|l|}{ Body mass index $\left(\mathrm{kg} / \mathrm{m}^{2}\right)$} \\
\hline$\leq 25$ & 88 & 60.5 & 0.99 & - & & - \\
\hline$<25$ & 34 & 55.7 & & - & - & \\
\hline \multicolumn{7}{|l|}{ Primary tumor location } \\
\hline Colon & 55 & 48.4 & $>0.99$ & - & & - \\
\hline Rectum & 67 & 53.2 & & - & - & \\
\hline \multicolumn{7}{|l|}{ Tumor stage ${ }^{a)}$} \\
\hline 1 & 5 & 66.7 & 0.08 & - & & - \\
\hline 2 & 24 & 74.3 & & - & & \\
\hline 3 & 72 & 49.4 & & - & & \\
\hline 4 & 21 & 29.9 & & - & - & \\
\hline \multicolumn{7}{|l|}{ Histology of primary tumor } \\
\hline Well differentiated & 12 & 37.3 & 0.89 & - & & - \\
\hline Moderately differentiated & 105 & 52.8 & & - & & \\
\hline Mucinous or poorly differentiated & 5 & 53.3 & & - & - & \\
\hline \multicolumn{7}{|l|}{ Previous hepatectomy } \\
\hline No & 108 & 53.8 & 0.12 & - & & - \\
\hline Yes & 14 & 23.4 & & - & - & \\
\hline \multicolumn{7}{|l|}{ Adjuvant therapy for CRC } \\
\hline No & 5 & 100.0 & 0.10 & - & & - \\
\hline Yes & 117 & 49.0 & & - & - & \\
\hline \multicolumn{7}{|l|}{ Disease-free interval (mo) } \\
\hline$<12$ & 21 & 25.8 & 0.01 & 1 & & 0.01 \\
\hline$\geq 12$ & 101 & 55.8 & & 0.298 & $0.149-0.598$ & \\
\hline \multicolumn{7}{|l|}{ No. of pulmonary tumors } \\
\hline Solitary & 77 & 60.9 & 0.01 & 1 & & 0.01 \\
\hline Multiple & 45 & 34.4 & & 2.451 & $1.285-4.674$ & \\
\hline \multicolumn{7}{|l|}{ Maximal tumor size (mm) } \\
\hline$\leq 20$ & 106 & 52.8 & 0.12 & - & & - \\
\hline$>20$ & 16 & 39.0 & & - & - & \\
\hline \multicolumn{7}{|l|}{ Distribution of metastases } \\
\hline Unilateral & 108 & 54.5 & 0.01 & 1 & & 0.97 \\
\hline Bilateral & 14 & 23.8 & & 1.014 & $0.418-2.463$ & \\
\hline \multicolumn{7}{|l|}{ Resection $^{\text {b) }}$} \\
\hline Non-anatomical & 90 & 50.1 & 0.79 & - & & - \\
\hline Anatomical & 32 & 52.9 & & - & - & \\
\hline \multicolumn{7}{|l|}{ Mediastinal LN dissection } \\
\hline No & 70 & 50.2 & 0.62 & - & & - \\
\hline Yes & 52 & 50.8 & & - & - & \\
\hline \multicolumn{7}{|l|}{ Mediastinal LN involvement } \\
\hline No & 44 & 58.6 & 0.01 & 1 & & 0.01 \\
\hline Yes & 8 & 0.0 & & 6.048 & 2.099-17.427 & 0.01 \\
\hline No data & 70 & 50.2 & & 1.014 & $0.418-2.463$ & 0.58 \\
\hline
\end{tabular}


Table 2. Continued

\begin{tabular}{|c|c|c|c|c|c|c|}
\hline Characteristic & $\begin{array}{c}\text { No. } \\
(n=122)\end{array}$ & $\begin{array}{c}5-Y_{\mathbf{r}} \\
\text { DFS (\%) }\end{array}$ & p-value & HR & $95 \% \mathrm{CI}$ & p-value \\
\hline \multicolumn{7}{|l|}{ Chemotherapy after PM } \\
\hline No & 11 & 68.2 & 0.58 & - & & - \\
\hline Cytotoxic agent only & 97 & 58.0 & & - & & \\
\hline Cytotoxic agent+targeted agent & 14 & 60.0 & & - & - & \\
\hline
\end{tabular}

DFS, disease-free survival; HR, hazard ratio; CI, confidence interval; CRC, colorectal cancer; LN, lymph node; PM, pulmonary metastasectomy. ${ }^{a}$ Using the seventh edition of the American Joint Committee on Cancer staging system, b) Non-anatomical resection included precision excision and wedge resection; anatomical resection included segmental resection and lobectomy.

pulmonary metastasectomy for metachronous PM, and 36 of 39 referred patients with metachronous PM who underwent CRC surgery at other hospitals underwent curative pulmonary metastasectomy at our hospital during the study period. Following exclusion of eight patients who underwent $\mathrm{R} 1$ or R2 resection, 122 patients were eligible for analysis.

There were significant differences in baseline characteristics between patients with synchronous PM and those with metachronous PM according to tumor stage of CRC, adjuvant therapy for CRC, number of prior regimens, and number and distribution of PM (Table 1). The median interval between primary CRC surgery and pulmonary metastasectomy in patients with synchronous and metachronous PM was 1.5 months (range, 0 to 25 months) and 24.0 months (rang, 4 to 86 months), respectively. However, there was no difference in survival rate between the two groups; the 5-year OS rates were $65.6 \%$ and $66.9 \%(p=0.57)$, respectively; the 5 -year DFS rates were $40.8 \%$ and $50.9 \%$ ( $\mathrm{p}=0.26$ ), respectively.

The mean age of patients with metachronous PM was $61.3 \pm 11.2$ years, and 83 patients $(68.0 \%)$ were male. Serum CEA level was available in 102/122 (83.6\%) patients, and missing in 20 cases because the patients had been referred. Of these, 64 patients had a normal serum CEA level, whereas 38 patients had a high serum CEA level. The primary CRC was located in the colon in 55 patients $(45.1 \%)$, and 14 patients $(11.5 \%)$ underwent curative hepatic resection for liver metastases during CRC surgery. The median DFI was 22.0 months (range, 4 to 85 months). Seventy-seven patients $(63.1 \%)$ had solitary PM, and the median maximum tumor size was $12.0 \mathrm{~cm}$ (range, 2 to $70 \mathrm{~cm}$ ). The types of pulmonary resection included precision excision $(28.7 \%)$, wedge resection $(45.1 \%)$, segmental resection $(9.8 \%)$, and lobectomy (16.4\%). Mediastinal LN dissection was performed in 52 patients $(42.6 \%)$, and eight of 52 patients $(15.4 \%)$ had mediastinal LN involvement. A total of 111 patients $(91.0 \%)$ received chemotherapy after pulmonary metastasectomy; 97 patients $(79.5 \%)$ received a cytotoxic agent only, and 14 patients $(11.5 \%)$ received a cytotoxic agent with a targeted agent (Table 1 ).

The median follow-up period after the first pulmonary metastasectomy was 27.5 months (range, 1 to 104 months). A total of 48 patients $(39.3 \%)$ had developed recurrent PM after initial pulmonary metastasectomy, including 39 patients with recurrent pulmonary metastases confined to the lungs and nine patients with multiple systemic metastases. Of 39 patients with pulmonary recurrence, only 10 patients had recurrences at previous resection sites. Pulmonary recurrence in the ipsilateral lung was detected in 12 patients, contralateral in 13, and bilateral in four. The 5-year DFS rate after initial pulmonary metastasectomy was $50.9 \%$. In univariable analysis, DFI, number of PMs, distribution of PMs, and mediastinal LN involvement were significantly prognostic of DFS. In multivariable analysis, DFI $\geq 12$ months, solitary lesions, and absence of mediastinal LN were independently prognostic of DFS (Table 2).

The 5-year OS rate in patients with recurrent PM was $56.3 \%$, and the median DFI for recurrent PM after the first pulmonary metastasectomy was 13.0 months (range, 1 to 38 months). Of the 48 patients with recurrent PM, 39 patients (81.2\%) underwent repeated pulmonary metastasectomy. In univariable analysis DFI of recurrent PM, number of PMs, and distribution of metastases were significantly prognostic of OS, whereas mediastinal LN involvement and chemotherapy after pulmonary metastasectomy were not significantly prognostic of OS. In multivariable analysis, DFI of recurrent PM was the only factor independently prognostic of OS in patients who underwent repeat pulmonary metastasectomy (Table 3).

Patients were divided into two subgroups according to DFI and number of PMs. The high-risk group $(n=70)$ was defined as patients with DFI $<12$ months, or multiple lesions, or mediastinal LN involvement, and the low-risk group $(\mathrm{n}=52)$ as patients with DFI $\geq 12$ months, solitary lesions, and absence of mediastinal LN involvement. The median DFI in the high- and low-risk groups was 15.0 months (range, 4 to 83 months) and 28.0 months (range, 13 to 85 months), respec- 
Table 3. Univariable and multivariable analysis of factors prognostic of 3-year OS following repeated pulmonary metastasectomy

\begin{tabular}{|c|c|c|c|c|c|c|}
\hline Characteristic & $\begin{array}{l}\text { No. } \\
(n=39)\end{array}$ & $\begin{array}{c}3-\mathbf{Y r} \\
\text { OS (\%) }\end{array}$ & p-value & HR & $95 \% \mathrm{CI}$ & p-value \\
\hline \multicolumn{7}{|l|}{ Age (yr) } \\
\hline$\leq 60$ & 20 & 44.1 & 0.40 & - & & - \\
\hline$>60$ & 19 & 64.4 & & - & - & \\
\hline \multicolumn{7}{|l|}{ Sex } \\
\hline Male & 30 & 59.0 & 0.15 & - & & - \\
\hline Female & 9 & 41.7 & & - & - & \\
\hline \multicolumn{7}{|l|}{ BMI $\left(\mathrm{kg} / \mathrm{m}^{2}\right)$} \\
\hline$\leq 25$ & 28 & 56.4 & 0.88 & - & & - \\
\hline$<25$ & 11 & 53.9 & & - & - & \\
\hline \multicolumn{7}{|l|}{ Primary tumor location } \\
\hline Colon & 21 & 62.4 & 0.97 & - & & - \\
\hline Rectum & 18 & 48.7 & & - & - & \\
\hline \multicolumn{7}{|l|}{ Tumor stage of CRC } \\
\hline 1 & 1 & - & 0.35 & - & & - \\
\hline 2 & 5 & 80.0 & & - & & \\
\hline 3 & 21 & 60.1 & & - & & \\
\hline 4 & 12 & 32.4 & & - & - & \\
\hline \multicolumn{7}{|l|}{ Histology of primary tumor } \\
\hline Well differentiated & 4 & 50.0 & 0.34 & - & & - \\
\hline Moderately differentiated & 33 & 58.5 & & - & & \\
\hline Mucinous or poorly differentiated & 2 & 50.0 & & - & - & \\
\hline \multicolumn{7}{|l|}{ Previous hepatectomy } \\
\hline No & 32 & 58.1 & 0.52 & - & & - \\
\hline Yes & 7 & 35.7 & & - & - & \\
\hline \multicolumn{7}{|l|}{ Recurrent DFI (mo) } \\
\hline$<12$ & 14 & 32.7 & 0.01 & 1 & & 0.01 \\
\hline$\geq 12$ & 25 & 70.5 & & 0.252 & $0.084-0.757$ & \\
\hline \multicolumn{7}{|l|}{ No. of recurrent PM } \\
\hline Solitary & 22 & 74.0 & 0.04 & 1 & & 0.29 \\
\hline Multiple & 17 & 29.1 & & 1.977 & $0.563-6.943$ & \\
\hline \multicolumn{7}{|c|}{ Maximal tumor size of recurrent PM (mm) } \\
\hline$\leq 20$ & 30 & 59.4 & 0.38 & - & & - \\
\hline$>20$ & 9 & 44.4 & & - & - & \\
\hline \multicolumn{7}{|l|}{ Distribution of recurrent PM } \\
\hline Unilateral & 35 & 64.1 & 0.01 & 1 & & 0.48 \\
\hline Bilateral & 4 & 25.0 & & 1.663 & $0.407-6.787$ & \\
\hline \multicolumn{7}{|l|}{ Repeated resection } \\
\hline Non-anatomical & 30 & 61.0 & 0.29 & - & & - \\
\hline Anatomical & 9 & 25.9 & & - & - & \\
\hline \multicolumn{7}{|l|}{ Mediastinal LN involvement } \\
\hline No & 14 & 58.9 & 0.95 & - & & - \\
\hline Yes & 5 & 60.0 & & - & & \\
\hline No data & 20 & 51.0 & & - & - & \\
\hline \multicolumn{7}{|l|}{ Chemotherapy after PM } \\
\hline No & 3 & 66.7 & 0.49 & - & & - \\
\hline Cytotoxic agent only & 31 & 58.9 & & - & & \\
\hline Cytotoxic agent+targeted agent & 5 & 30.0 & & - & - & \\
\hline
\end{tabular}

OS, overall survival; $\mathrm{HR}$, hazard ratio; $\mathrm{CI}$, confidence interval; $\mathrm{BMI}$, body mass index; $\mathrm{CRC}$, colorectal cancer; $\mathrm{DFI}$, disease free interval; PM, pulmonary metastases; LN, lymph node. 
Table 4. Comparison of clinical characteristics in the high- and low-risk subgroups

\begin{tabular}{|c|c|c|c|}
\hline Characteristic & $\begin{array}{l}\text { High-risk group }{ }^{a)} \\
\quad(n=70)\end{array}$ & $\begin{array}{c}\text { Low-risk group }^{\mathrm{b})} \\
\quad(\mathrm{n}=52)\end{array}$ & p-value \\
\hline \multicolumn{4}{|l|}{ Age (yr) } \\
\hline$\leq 60$ & $34(48.6)$ & $21(40.4)$ & 0.46 \\
\hline$>60$ & $36(51.4)$ & $31(59.6)$ & \\
\hline Mean \pm SD & $60.5 \pm 11.2$ & $62.3 \pm 11.1$ & 0.38 \\
\hline \multicolumn{4}{|l|}{ Sex } \\
\hline Male & $48(68.6)$ & $35(67.3)$ & $>0.99$ \\
\hline Female & $22(31.4)$ & $17(32.7)$ & \\
\hline \multicolumn{4}{|l|}{ BMI $\left(\mathrm{kg} / \mathrm{m}^{2}\right)$} \\
\hline$\leq 25$ & $50(71.4)$ & $38(73.1)$ & $>0.99$ \\
\hline$<25$ & $20(28.6)$ & $14(26.9)$ & \\
\hline Mean \pm SD & $23.3 \pm 3.2$ & $23.6 \pm 2.9$ & 0.61 \\
\hline \multicolumn{4}{|l|}{ Primary tumor location } \\
\hline Colon & $34(48.6)$ & $21(40.4)$ & 0.46 \\
\hline Rectum & $36(51.4)$ & $31(59.6)$ & \\
\hline \multicolumn{4}{|l|}{ Tumor stage of CRC } \\
\hline $1-3$ & $50(71.4)$ & $48(92.3)$ & 0.01 \\
\hline 4 & $20(28.6)$ & $4(7.7)$ & \\
\hline \multicolumn{4}{|c|}{ Histology of primary tumor } \\
\hline Well & $6(8.6)$ & $6(11.5)$ & 0.14 \\
\hline Moderately & $59(84.3)$ & $46(88.5)$ & \\
\hline Mucinous or poorly & $5(7.1)$ & 0 & \\
\hline \multicolumn{4}{|l|}{ Previous hepatectomy } \\
\hline No & $58(82.9)$ & $50(96.2)$ & 0.02 \\
\hline Yes & $12(17.1)$ & $2(3.8)$ & \\
\hline \multicolumn{4}{|c|}{ Adjuvant therapy for CRC } \\
\hline No & $2(2.9)$ & $3(5.8)$ & 0.65 \\
\hline Yes & $68(97.1)$ & $49(94.2)$ & \\
\hline \multicolumn{4}{|l|}{ DFI (mo) } \\
\hline$<12$ & $21(30.0)$ & 0 & $<0.001$ \\
\hline$\geq 12$ & $49(70.0)$ & $52(100)$ & \\
\hline Median (range) & $15.0(4-83)$ & $28.0(13-85)$ & \\
\hline \multicolumn{4}{|c|}{ No. of pulmonary tumors } \\
\hline Solitary & $25(35.7)$ & $52(100)$ & $<0.001$ \\
\hline Multiple & $45(64.3)$ & 0 & \\
\hline Median (range) & $2.0(1-14)$ & 1.0 & \\
\hline \multicolumn{4}{|c|}{ Maximal tumor size (mm) } \\
\hline$\leq 20$ & $58(82.9)$ & $48(92.3)$ & 0.18 \\
\hline$>20$ & $12(17.1)$ & $4(7.7)$ & \\
\hline Median (range) & $13.5(2-70)$ & $10.0(3-38)$ & \\
\hline \multicolumn{4}{|c|}{ Distribution of metastases } \\
\hline Unilateral & $56(80.0)$ & $52(100)$ & $<0.001$ \\
\hline Bilateral & $14(20.0)$ & 0 & \\
\hline \multicolumn{4}{|l|}{ Resection } \\
\hline Non-anatomical & $51(72.9)$ & $39(75.0)$ & 0.84 \\
\hline Anatomical & $19(27.1)$ & $13(25.0)$ & \\
\hline \multicolumn{4}{|c|}{ Mediastinal LN involvement ${ }^{c}$} \\
\hline No & $27(77.1)$ & $17(100)$ & 0.04 \\
\hline Yes & $8(22.9)$ & 0 & \\
\hline
\end{tabular}


Table 4. Continued

\begin{tabular}{lccc} 
Characteristic & $\begin{array}{c}\text { High-risk group } \\
(\mathbf{n}=70)\end{array}$ & $\begin{array}{c}\text { Low-risk group }{ }^{\mathrm{b})} \\
(\mathbf{n}=52)\end{array}$ & $\mathrm{p}^{-\mathrm{value}}$ \\
Recurrent PM & & & \\
No & $32(45.7)$ & $42(80.8)$ & $<0.001$ \\
Yes & $38(54.3)$ & $10(19.2)$ & \\
\hline
\end{tabular}

Values are presented as number (\%) unless otherwise indicated. SD, standard deviation; BMI, body mass index; CRC, colorectal

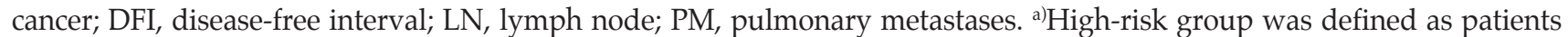
with DFI $<12$ months, or multiple PM, or mediastinal LN involvement, ${ }^{b}$ Low-risk group was defined as patients with DFI $\geq 12$ months, solitary lesions, and absence of mediastinal LN involvement, ${ }^{c}$ Including 52 patients who underwent mediastinal LN dissection.

A

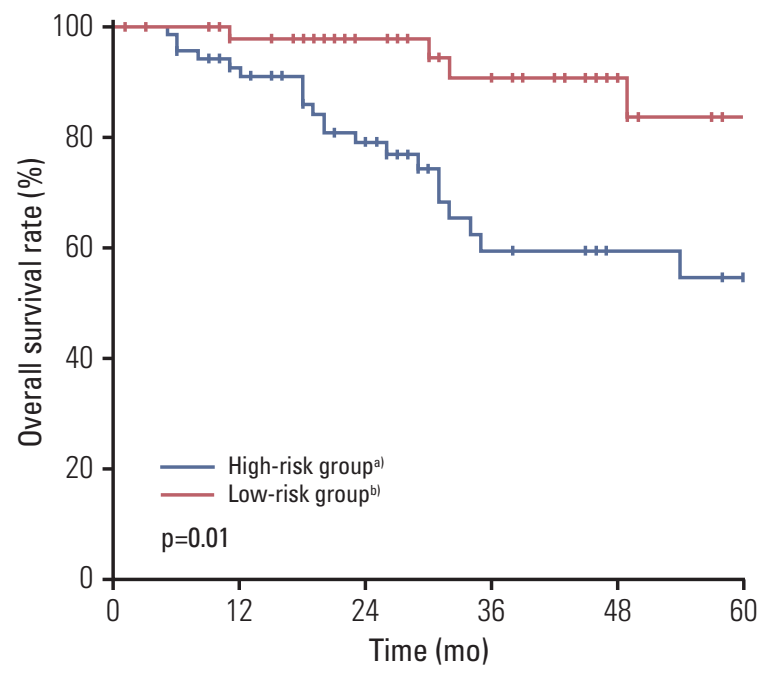

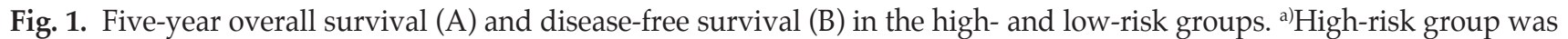
defined as patients with disease-free interval (DFI) $<12$ months, or multiple pulmonary metastases, or mediastinal lymph node (LN) involvement, ${ }^{b}$ Low-risk group was defined as patients with DFI $\geq 12$ months, solitary lesions, and absence of mediastinal LN involvement.

tively. The median number of PMs was 2.0 (range, 2 to 14 ) in the high-risk group. Of 70 patients $(54.3 \%)$ in the high-risk group, 38 patients developed recurrent PM after initial pulmonary metastasectomy compared with 10 of $52(19.2 \%)$ in the low-risk group $(\mathrm{p}<0.001)$. Development of recurrent PM occurred within 12 months in 16 of 38 patients $(42.1 \%)$ in the high-risk group, compared with three of $10(30.0 \%)$ in the low-risk group. The high- and low-risk groups differed significantly in stage of CRC, distribution of PM and recurrent PM, whereas there was no significant difference in the percentage who received adjuvant chemotherapy (Table 4). OS and DFS rate also showed significant difference in the two groups (Fig. 1).

\section{Discussion}

This study demonstrates the potential benefit of curative pulmonary metastasectomy for survival in patients with metachronous PM from CRC. Our results showed that DFI, number of pulmonary lesions, and mediastinal LN involvement were independent prognostic factors in patients with CRC who underwent curative pulmonary metastasectomy. In addition, better survival rates were observed for patients with recurrent $\mathrm{PM} \geq 12$ months compared to those who developed recurrent $\mathrm{PM}<12$ months after pulmonary metastasectomy. 
We observed 5-year OS and DFS rates of 66.4\% and 50.9\%, respectively; this OS rate is at the high end of the range of previously reported 5-year OS rates (30\% to 68\%) [18]. However, the current study only included patients with metachronous lesions who underwent $\mathrm{R} 0$ resection. These findings suggest that patients should be carefully selected by strict multimodal assessment of the probability of R0 pulmonary metastasectomy.

Various factors, including number of pulmonary lesions, patient age, stage of the primary tumor, history of liver resection, maximum tumor size, histology of the primary tumor, DFI, and CEA level, have been associated with the prognosis of patients who undergo pulmonary metastasectomy $[2,7,14]$; however, the results remain controversial because of the heterogeneity of selection criteria and variations in multimodal treatment [19]. Therefore, only patients with metachronous PM who underwent R0 resection were assessed, since it is important to determine whether pulmonary resection offers a chance of cure.

There is no definite consensus regarding synchronous and metachronous PM. In previous studies lesions detected prior to or within 3 months after CRC surgery were defined as synchronous PM [15], whereas in some studies lesions detected at least 6 months after the primary resection were defined as synchronous PM [14]. The first opportunity for follow-up imaging study usually occurred at 3 months after the primary CRC surgery; therefore, metachronous PM was defined as a new lesion detected at least 4 months after primary CRC surgery.

DFI has been reported to be prognostic of pulmonary metastasectomy for PM from CRC [14]; however, various cut-off values have been used to define short DFI, and the correlation between DFI and survival rate was not determined in several studies $[7,20]$. The mechanism underlying this finding may be related to the time of detection of disease progression, or earlier metastasis may represent a more disseminated disease and tendency to spread than later metastasis [21]. Our results showed that DFI was independently prognostic of pulmonary metastasectomy for PM. Therefore, careful follow-up is required after pulmonary metastasectomy for patients who develop PM less than 1 year after primary tumor resection.

Similar to previous studies, we observed significantly better prognosis for patients with a solitary pulmonary lesion than for those with multiple lesions [8], although several studies found no significant association between prognosis and number of PMs $[4,13]$. Multiple lesions may increase the likelihood of widespread undetected tiny nodules throughout the lungs or even in other distant organs. Therefore, meticulous preoperative staging for PM is critical in detection of occult metastatic lesions.

Several studies suggested an association of mediastinal LN involvement with an increased risk of death $[6,13]$ and a meta-analysis showed poor 5-year survival in the group with $\mathrm{LN}$ involvement (range, $0 \%$ to $33.5 \%$ ) compared to those with no thoracic LN metastases (range, 38.7\% to 71\%) [19]. However, mediastinal LN was not routinely performed in most studies. Our results showed that mediastinal LN involvement was a significantly prognostic factor for DFS in univariable and multivariable analysis, although there were no differences in DFS between patients who underwent mediastinal LN dissection and those who did not. Therefore, we suggest that mediastinal LN dissection could be performed in patients with expected LN involvement who show an enlarged LN on preoperative chest CT or hypermetabolic lesion on PET-CT.

This study also identified a subgroup of patients, based on DFI and number of PMs, who are expected to benefit most from pulmonary metastasectomy. A significantly higher recurrent PM rate was observed in the high risk group compared with the low-risk group (54.3\% vs. $19.2 \%, \mathrm{p}<0.001$ ), suggesting that pulmonary metastasectomy might have the greatest benefit in the low-risk group. Careful attentive surveillance based on a regular follow-up schedule may result in early identification of these patients.

Repeated pulmonary metastasectomy has been found to offer a chance for long-term survival to patients with prolonged DFI after initial pulmonary metastasectomy [22], a solitary recurrent pulmonary lesion [23], and normal CEA level [17]. In addition, a recent meta-analysis reported a 5year survival rate of $57.9 \%$ for patients who underwent repeated pulmonary metastasectomy [21], perhaps because these patients were highly selected, based on initial resection of PM. In our study a better prognosis was observed for patients with longer recurrent DFI than for patients with shorter recurrent DFI, whereas OS rate was not affected by treatment of recurrent PM with chemotherapy and surgical intervention. Therefore, repeated pulmonary metastasectomy in selected patients in whom the capacity of the remnant lung parenchyma could be preserved after resection may be a valuable alternative to palliative chemotherapy.

There was no definite consensus regarding recurrent DFI of recurrent PM, as DFI after the first pulmonary metastasectomy. Park et al. [17] reported that recurrent DFI was dichotomized before and after 12 months, whereas two other studies could not set the cut-off value of recurrent DFI, in which median recurrent DFI was 14 months (range, 4.0 to 29.0 months) and 16.8 months (range, 2.0 to 38.2 months), respectively $[22,23]$. Our results showed a median recurrent DFI of 13.0 months (range, 4.0 to 31.0 months). Therefore, we used the cut-off value of 12 months for recurrent DFI, as reported in a previous study [17].

Similar to the number of PMs, bilateral PM $[6,22]$ and larger PM size [8] may indicate a greater likelihood of the 
presence of other undetectable metastatic lesions. However, in a previous study bilateral PM had no effect on OS [24], and most studies found no significant association between survival and PM size [19]. The current study found no association between these factors and survival rate. These findings suggest that bilateral PM and larger PM size that can be completely resected are not contraindications for pulmonary metastasectomy.

Several studies have reported better survival outcomes for patients with metachronous PM compared to those with synchronous PM, the latter being considered more aggressive [6]; however, it remains controversial [15]. In the current study, it did not appear that patients treated with metachronous PM had longer survival compared to those with synchronous PM, although patients with synchronous PM had more aggressive primary tumor stage, multiple PMs, and bilateral PMs. This might be due to the fact that only patients who underwent pulmonary metastasectomy for synchronous PM were included, because of the study limitation by retrospective design. Nevertheless, survival outcomes did not differ between patients who underwent pulmonary metastasectomy for synchronous PM and those who underwent pulmonary metastasectomy for metachronous PM. Therefore, pulmonary metastasectomy might be feasible in selected patients with either synchronous or metachronous PM.

Previous studies have reported on the usefulness of chest CT scan for detection of lung nodules, with $>70 \%$ sensitivity for detection of suspicious pulmonary metastatic nodules from CRC [25]. However, it does not appear to show correlation with an equal specificity, which may cause difficulty in interpreting the nature of a pulmonary lesion, because pathologic confirmation is too difficult or occasionally risky in most cases, particularly for small lesions. Therefore, we have used the regular follow-up program for patients with PM from CRC in accordance with National Comprehensive Cancer Network guidelines, and treatment decisions were made by the MDT.

This study had some limitations. First, there was a potential for selection bias, compounded by the retrospective design. Inclusion of patients was highly selective, with presumed good performance status, and fewer comorbidities, which might have contributed to the demonstrated longterm survival. Second, in this study chemotherapy after pulmonary metastasectomy did not appear to be significantly prognostic of OS, which may affect survival rate. Nevertheless, surgical resection of PM and recurrent PM after primary pulmonary metastasectomy was feasible for patients with or without systemic chemotherapy. In addition, we identified prognostic factors of survival in patients who underwent complete resection for metachronously developed PM, and divided them according to high- and low-risk groups using these factors. Further large-scale prospective studies will be helpful in verifying our results.

\section{Conclusion}

In conclusion, there is a potential survival benefit for patients with metachronous PM from CRC who undergo pulmonary metastasectomy, even those with recurrent pulmonary metastases. These findings suggest that pulmonary metastasectomy might benefit carefully selected patients, particularly those with longer DFI, solitary lesions, and absence of mediastinal LN involvement.

\section{Conflicts of Interest}

Conflict of interest relevant to this article was not reported.

\section{Acknowledgments}

We thank the Medical Research Collaborating Center (MRCC) in Seoul National University Bundang Hospital for their kind assistance in the process of statistical analysis for this study.

\section{References}

1. Gatta G, Faivre J, Capocaccia R, Ponz de Leon M. Survival of colorectal cancer patients in Europe during the period 19781989. EUROCARE Working Group. Eur J Cancer. 1998;34: 2176-83.
2. Zink S, Kayser G, Gabius HJ, Kayser K. Survival, disease-free interval, and associated tumor features in patients with colon/ rectal carcinomas and their resected intra-pulmonary metastases. Eur J Cardiothorac Surg. 2001;19:908-13. 
3. August DA, Ottow RT, Sugarbaker PH. Clinical perspective of human colorectal cancer metastasis. Cancer Metastasis Rev. 1984;3:303-24.

4. McCormack PM, Burt ME, Bains MS, Martini N, Rusch VW, Ginsberg RJ. Lung resection for colorectal metastases: 10-year results. Arch Surg. 1992;127:1403-6.

5. Iwasaki A, Shirakusa T, Yamashita Y, Noritomi T, Maekawa T, Hamada T. Characteristic differences between patients who have undergone surgical treatment for lung metastasis or hepatic metastasis from colorectal cancer. Thorac Cardiovasc Surg. 2005;53:358-64.

6. Inoue M, Ohta M, Iuchi K, Matsumura A, Ideguchi K, Yasumitsu T, et al. Benefits of surgery for patients with pulmonary metastases from colorectal carcinoma. Ann Thorac Surg. 2004; 78:238-44.

7. Girard P, Ducreux M, Baldeyrou P, Rougier P, Le Chevalier T, Bougaran J, et al. Surgery for lung metastases from colorectal cancer: analysis of prognostic factors. J Clin Oncol. 1996;14: 2047-53.

8. Vogelsang H, Haas S, Hierholzer C, Berger U, Siewert JR, Prauer $\mathrm{H}$. Factors influencing survival after resection of pulmonary metastases from colorectal cancer. Br J Surg. 2004;91: 1066-71.

9. Simmonds PC. Palliative chemotherapy for advanced colorectal cancer: systematic review and meta-analysis. Colorectal Cancer Collaborative Group. BMJ. 2000;321:531-5.

10. Seymour MT, Stenning SP, Cassidy J. Attitudes and practice in the management of metastatic colorectal cancer in Britain. Colorectal Cancer Working Party of the UK Medical Research Council. Clin Oncol (R Coll Radiol). 1997;9:248-51.

11. National Comprehensive Cancer Network. NCCN guidelines version 3. Colon Cancer [Internet]. Fort Washington, PA: National Comprehensive Cancer Network; 2013 [cited 2012 Nov 26]. Available from: http://www.nccn.org/professionals / physician_gls/f_guidelines.asp.

12. Wolpin BM, Mayer RJ. Systemic treatment of colorectal cancer. Gastroenterology. 2008;134:1296-310.

13. Saito Y, Omiya H, Kohno K, Kobayashi T, Itoi K, Teramachi $\mathrm{M}$, et al. Pulmonary metastasectomy for 165 patients with colorectal carcinoma: a prognostic assessment. J Thorac Cardiovasc Surg. 2002;124:1007-13.

14. Rena O, Casadio C, Viano F, Cristofori R, Ruffini E, Filosso PL, et al. Pulmonary resection for metastases from colorectal cancer: factors influencing prognosis: twenty-year experience. Eur J Cardiothorac Surg. 2002;21:906-12.

15. Mitry E, Guiu B, Cosconea S, Jooste V, Faivre J, Bouvier AM. Epidemiology, management and prognosis of colorectal cancer with lung metastases: a 30-year population-based study. Gut. 2010;59:1383-8.

16. Cho S, Song IH, Yang HC, Jheon S. Prognostic factors of pulmonary metastasis from colorectal carcinoma. Interact Cardiovasc Thorac Surg. 2013;17:303-7.

17. Park JS, Kim HK, Choi YS, Kim K, Shim YM, Jo J, et al. Outcomes after repeated resection for recurrent pulmonary metastases from colorectal cancer. Ann Oncol. 2010;21:1285-9.

18. Simmonds PC, Primrose JN, Colquitt JL, Garden OJ, Poston GJ, Rees M. Surgical resection of hepatic metastases from colorectal cancer: a systematic review of published studies. Br J Cancer. 2006;94:982-99.

19. Pfannschmidt J, Dienemann H, Hoffmann H. Surgical resection of pulmonary metastases from colorectal cancer: a systematic review of published series. Ann Thorac Surg. 2007;84: 324-38.

20. Sakamoto T, Tsubota N, Iwanaga K, Yuki T, Matsuoka H, Yoshimura M. Pulmonary resection for metastases from colorectal cancer. Chest. 2001;119:1069-72.

21. Salah S, Watanabe K, Park JS, Addasi A, Park JW, Zabaleta J, et al. Repeated resection of colorectal cancer pulmonary oligometastases: pooled analysis and prognostic assessment. Ann Surg Oncol. 2013;20:1955-61.

22. Chen F, Sakai H, Miyahara R, Bando T, Okubo K, Date H. Repeat resection of pulmonary metastasis is beneficial for patients with colorectal carcinoma. World J Surg. 2010;34: 2373-8.

23. Welter S, Jacobs J, Krbek T, Krebs B, Stamatis G. Long-term survival after repeated resection of pulmonary metastases from colorectal cancer. Ann Thorac Surg. 2007;84:203-10.

24. Riquet M, Foucault C, Cazes A, Mitry E, Dujon A, Le Pimpec Barthes F, et al. Pulmonary resection for metastases of colorectal adenocarcinoma. Ann Thorac Surg. 2010;89:375-80.

25. Murata K, Takahashi M, Mori M, Kawaguchi N, Furukawa A, Ohnaka Y, et al. Pulmonary metastatic nodules: CT-pathologic correlation. Radiology. 1992;182:331-5. 